\title{
Research on Current Situation and Countermeasures of English Teaching in Independent Colleges_-Based on Application-oriented Universities Transformation
}

\author{
Yiyin Liang \\ ${ }^{1}$ School of Foreign Languages, Zhejiang University of Finance and Economics Dongfang College, Jiaxing, Zhejiang \\ Province, 314400, China. \\ *Corresponding author. Email: $984060445 @ q q . c o m$
}

\begin{abstract}
With the continuous development of independent colleges and the increase of the demand for interdisciplinary talents in China, it has become a general choice for independent colleges to transform into application-oriented universities. In this process, English teaching in independent colleges increasingly highlights its importance and becomes one of the key topics in this period. Starting with the current teaching situation of English Majors in independent colleges, this paper analyzed the problems existing in their education program, curriculum setting and students' learning situation. And this paper combined the needs of local economic development with the theoretical guidance of the transformation of Knowledge Production Mode to put forward some suggestions on the improvement of curriculum, educational concept and educational system of independent colleges. This transformation is a systematic project. In the process of transformation, the school should proceed from reality and make rational use of its superior resources to find a school-based personnel training mode of applied English talents. Meanwhile, the college needs to insist on persistently innovating and promoting the teaching system of various aspects, so as to effectively improve the quality of College English teaching and cultivate high-level applied talents who satisfy the requirements of the era of the knowledge economy.
\end{abstract}

Keywords: Independent college, College English teaching, Application-oriented universities, Independent college transformation, English major

\section{INTRODUCTION}

It is critical to lead some independent colleges to transform into application-oriented schools in order to meet the needs of high-level application-oriented talents in China's rapid economic development and to promote the popularization of higher education in China. In general, Chinese independent colleges are more likely to focus on application-oriented teaching. Additionally, most of these schools intend to transform into a total individual application-oriented university because they in response to the call of the Ministry of Education to accelerate the transformation that independent colleges must separate from the main campus. This transformation is a major reform concerning the social system, educational concept and talent training pattern. After the exploration and practice of English major teaching under the applied teaching mode, the independent college has accumulated some rudimentary experience. However, there are still some challenges and difficulties in the applied education, especially in English language teaching of application-oriented universities that cannot be ignored. This paper will analyze the current situation of English teaching for English majors under the background of the transformation of independent colleges, trying to find problems and put forward advice for the cultivation of English-applied talents.

\section{REALISTIC BACKGROUND OF APPLICATION-ORIENTED ENGLISH TEACHING IN INDEPENDENT COLLEGES}

There are various reasons why most independent colleges tend to application-oriented education. First of all, the emergence of application-oriented universities is 
a revision and improvement of the education model of traditional colleges and universities. It is a way to make up for the shortage of practical education in Chinese higher education. Based on the integration of vocational education, mass education and academic education, the application-oriented university promotes the combination of social production and academic research. To some extent, it can alleviate the urgent demand of this economic society for high-level applied talents.[1]

Meanwhile, the transformation to an application-oriented university also alleviates the survival and development problems encountered by most independent colleges. As for the goal of English education in independent colleges, students need to gain the understanding of language and comprehensive application ability from many angles. In this case, under the background of shortage of superior educational resources and academic foundation, the emphasis of education on cultivating practical talents who can directly use what they have learned to serve the public can increase the competitiveness of the independent colleges.

In addition, the talent evaluation of application-oriented universities is more diversified. Therefore, with the introduction of application-oriented teaching, the English majors can have more understanding of their current learning situation and shortcomings, and improve the ability that they can combine the theory with practice.

\section{ANALYSIS OF THE PROBLEMS OF ENGLISH TEACHING IN INDEPENDENT COLLEGES}

At present, the independent college has made some achievements during this transformation, but the systematization of its transformation and development in English teaching is inadequate. There is still a gap between the actual learning situation of students and the training target of application-oriented talents. The following problems still can be seen in the current teaching situation

\subsection{Inadequate Implementation of the Training Program}

The schools provide a variety of professional directions in the training program for English majors, such as economic and trade management, cross-border e-commerce, English education, translation and so on. However, in the real teaching process, only business English teaching and general English teaching are usually involved. Students need to learn a wide range of courses that involve many directions but less targeted. However, due to the inadequate diversion and the late start of professional courses in specific directions, students will have a long period of confusion. During this time, they are unable to find the difference between these professional directions, and the significance of diversion is also greatly reduced. In the later stage, although the school has set up practical training courses for different professional directions in the senior year, its class hours are short, which is more experiential than academic for students. In addition, in previous courses, students lack the study of specific professional courses, so it is difficult for students to refine in a specific direction. Meanwhile, it is also a hard task for students to apply more extensive knowledge quickly when participating in practical training courses through only a short transition period that they need to combine theory and practice. Additionally, due to the unclear and inadequate implementation of the major direction, students cannot get notable help in the future employment.

\subsection{Lack of Application-oriented Curriculum}

There is little content involving practice and application in the school's current curriculum, and theory is still the main content, so students do not have the opportunity to exercise their language ability.

\subsubsection{Reducing Class Hours Blindly during the Transition}

The General Office of the State Council of the People's Republic of China has given some suggestions saying that in order to cultivate high-level innovative talents, the colleges and universities should further deepen the reform of creative education in universities and promote the education concepts and talent training mode. According to these views, some of the major courses are replaced by creation and innovation-related courses. However, the curriculum reform is not in place, which has led to the limitation of the courses. These courses only related to the business education instead of arranging by the different needs of different majors. As for some majors with low relevance with this business, such as English major, the low flexibility of these courses leads to not only the reducing the time for learning specialized courses, but also the waste of the opportunity to improve English application ability.

\subsubsection{Outdated Teaching Materials}

The textbooks of some specialized subjects are outdated, which is not conducive to the students to build a good connection between the knowledge acquired in the textbooks and the practical application, and even contrary to the aim of application-oriented talents training. The outdated textbooks also make it difficult for students to resonate with the cases of the textbooks, which makes them unable to rise interest in English language learning. Language is constantly changing and updating, and the replacement of popular and proper 
words will be reflected in the actual use, thus the requirements for real-time teaching materials need to be relatively high. Because the cases in the current textbooks are outdated and the classification is not clear, it is difficult for students to do comprehensive practice on one specific angle. For this reason, the knowledge students gain from the class may be disconnected from the society. Moreover, in order to make up for the defects of the outdated teaching materials, teachers often use extra-curricular materials to make a supplement, which has caused a certain burden for both teachers and students.

\subsection{Current Situation of Students' learning}

The students in independent colleges are on various levels of English learning. For most of them, their basic English knowledge, study habits and attitudes are not good enough.

\subsubsection{Students Lack Enthusiasm for English Learning}

Due to the influence of external factors such as limited cognition and outdated teaching materials, students in independent colleges are generally not interested in English learning. Most students still learn in a passive way, so it is difficult for them to use the knowledge actively and flexibly. Long-term accumulation is one of the key points in learning English. Therefore, the students cannot use the English expertly if they only exercise their English language abilities in class passively.

\subsubsection{Students' \\ cultural Consciousness of English is Weak}

Students do not have enough understanding about the cultural background of the English language, thus they cannot recognize the correct and deep meaning behind the language very well. For this reason, they may have low accuracy when they are using this language application and they may cause misunderstanding easily. Especially in the use of English words, students tend to remember and use them only according to their Chinese definitions, but ignoring the cultural connotation behind the words, which will lead to a series of problems such as improper collocation of words or the use of the obsoleted words at present. The meaning of the same word may change in different contexts, because the words have accumulated rich cultural connotations in their long-term use, all of which involve western customs, religious beliefs and historical culture. Moreover, when students are unable to understand the cultural connotation of English-speaking countries and the thinking patterns of English people, they can hardly use English more idiomatically, and may even cause serious problems such as cultural prejudice and discrimination.

\section{FEASIBLE MEASURES TO IMPROVE ENGLISH TEACHING}

\subsection{Introduce More Specific Specialized Courses}

According to the internal factors like the needs of students and external factors such as the training programs and local economic and social development needs, more distinctive and professional courses should be set up. the colleges can design more professional curriculum according to students' different professional directions, especially in the later term. Under the promise of respecting students' interests, the school can cooperate with local enterprises and institutions to establish a cooperation platform of Industry-college-research[2]. They can make a connection between industry and education to promote the synchronous development of both English majors of the school and regional industry. Enterprises can provide students with practical training opportunities and practice projects corresponding to their major, so as to help students exercise their language ability. In this case, students can get real-time feedback and guidance from teachers during school time. With actual circumstances for English ability exercising, students can reduce the time which they spend in seeking practical training opportunities, and they can also integrate into the workplace more quickly in the future. Additionally, through the cooperation of Enterprises and colleges, the school can keep pace with the developmental trend of the industry and make more actual and specific plans for application-oriented teaching. Moreover, in the process of cooperation, enterprises can not only get technical support from universities, but also improve their reputation among students, which is of great help to the recruitment of talents in the future. Therefore, this cooperation is a win-win for schools and enterprises.

\subsection{Make Full Use of schools' characteristics and Resources}

In the characteristic development of application-oriented universities, it is necessary to analyze the foundations, characteristics and advantages of the schools comprehensively and integrate superior resources. The main campuses of some independent colleges have particular characteristics or superior majors, which provides the possibility for the cultivation of interdisciplinary talents with not only English language skills but knowledge of other different majors. The colleges can also build an integrated system of the resource. According to $\mathrm{M}$. Gibbons' transformation theory of knowledge production, knowledge production is not simply the accumulation of discipline knowledge, 
but the integration of existing knowledge resources under the current situation. It requires that the boundaries between disciplines need to be more blurred and their division of labor and integration need to be strengthened[3]. Therefore, the colleges can also make full use of available resources and introduce and improve existing training courses in advance, for example, they can make full use of the school's innovation and entrepreneurship project and try to combine English skills into the project. With the mode of combination of theory area and practical area, students can receive more practical practice and more professional guidance. In addition, the teaching team can be further improved. In order to provide effective guarantees of teachers for the school-based college English curriculum system, colleges need to establish a suitable and sustainable teaching team according to the different courses[4]. College English teachers should be competent in teaching more than one course of applied English, for the reason that they can provide experience about accessing compound knowledge in a better way. While ensuring the exercise of English application ability, teachers can also introduce bilingual courses in various directions to promote the construction of interdisciplinary classes.

\subsection{Improve the Teaching Concept and Teaching System}

\subsubsection{Value the Humanism of Language in Language Teaching}

In the application-oriented teaching goal of the English language, cultivating students' cross-cultural communication ability is necessary, because the implementation of culture teaching is one of the key points to achieve the purpose of language teaching. Learning the cultural background of English will help students to recognize and understand the world from different angles, so that they can treat cultural differences correctly and eliminate prejudice and discrimination[5]. It is difficult to understand the actual meaning of the language without understanding the culture behind the language, because language does not exist without a specific cultural background. In the context of application-oriented teaching, it is easy to regard English only as a medium and tool of communication, but ignore its humanity.

Meanwhile, as the organizers of the class, teachers of independent colleges should also constantly improve their cultural consciousness of English. On the basis of theoretical teaching, teachers can combine the introduce pragmatic context into the class to create cultural circumstances. Students will be able to truly feel and integrate into the scene as a result, and their understanding of cultural phenomena will improve. Teachers can also instruct more cultural-related knowledge in language teaching to encourage students' cross-cultural thinking. In addition, according to the ICC model proposed by Professor Byram, successful two-way communication requires people to be familiar with the target culture and native culture at the same time[6]. While helping students to understand the western culture, teachers should also integrate traditional Chinese culture into it to achieve two-way communication between different cultures, consequently, students can improve their language skills while retaining their cultural confidence. Moreover, the introduction of local culture into English teaching can make students resonate and understand the knowledge they have learned more easily and can also improve students' interest in English learning. In this way, teachers can guide students to participate in class and maximize the benefit of classroom teaching.

\subsubsection{Schools Should Improve the Education System}

According to the theory put forward by M. Gibbons, we can know that the Knowledge Production Mode is changing, which means it is gradually changing from Knowledge Production Mode I to Knowledge Production Mode II. The traditional research and education model is becoming more and more inappropriate to satisfy the requirements of the era of knowledge economy[7]. During this change, the university gradually loses its position as the center of knowledge production. The globalization of business competition and technical competition make new knowledge providers constantly emerge, such as research and development centers of enterprises, think tanks of Chinese government, social consulting institutions[8] and so on. In order to adapt to the increasingly creative economy and society[9], their demand for new knowledge and technology has exceeded the supply of any single major or university. Additionally, the teaching quality evaluation system has become more diversified, and the quality control of knowledge production process and the evaluation of professionals' achievements begin to adopt the public's opinion.

Therefore, due to its application-based scenarios and interdisciplinary features, the Knowledge Production Mode II is more suitable for the educational aims and teaching concepts of current application-oriented universities. According to this guiding concept, schools should constantly improve the current education system and form a teaching program based on general English and expanded English education for professional purposes. In addition, schools should try to build a practical training mode of Industry-University-Research and strengthen the cooperation among schools, enterprises, and local governments for promoting the 
connection and development between industry innovation chains and interdisciplinary talents chains.

\section{CONCLUSION}

The reform of independent college English teaching transform to actual application-oriented teaching is a complex and systematic project, which cannot do without a reasonable curriculum setting, advanced teaching concepts, and a mature educational system. The ultimate goal of application-oriented teaching can only be achieved through coordinated development of various aspects. However, in the process of transformation, there are still some key issues that have not been overcome. Some schools are still unable to get rid of the inertial thinking from the traditional university management and lack the further breakthroughs in educational concepts. What's more, there are also problems about the imbalance of cooperative relations in the combination of industry and education. All in all, the college should proceed from the reality and combine its own situation with the local economic environment to find a personnel training mode of applied English talents that is suitable for the actual situation of the school. Only in this way, the independent colleges can improve the quality of college English teaching more effectively and cultivate more high-level practical personnel who can contribute and be responsible for society.

\section{REFERENCES}

[1] Hu, T.Y. (2013) Logic and Problems of the Construction of Application-oriented University. China Higher Education Research, 000(005): 2631.

[2] He Y. (2020) Research on Practical Training Mode of Industry-University-Research Integration for English Majors - A Case of the Reform in the School of Foreign Languages, Guangxi University of Science and Technology. Jiangsu higher vocational education, 20 (4): 78-83.

[3] Gibbons, M. (2011) The New Production of Knowledge: The Dynamics of Science and Research in Contemporary Societies. Peking University Press, Beijing.

[4] Wan C.H., Zhang L. (2020) Current Situation and Countermeasures of College English Teaching in Local Colleges and Universities. Chinese Journal of Multimedia and Network Teaching: Electronic Edition, 6(4): 69-70.

[5] Xue, M.M. (2019). Culture Cultivation and Infiltration in College English Teaching. Literature Education (2), 000 (004), 70-71.
[6] Byram M., Masuhara H. (2013) Intercultural Competence. In: Tomlinson B. (Eds.), Applied Linguistics and Materials Development. Bloomsbury Publishing, London. 143-159.

[7] Gibbons, M., Scott, P., Grosjean, J.A., Cayley, D. (2016). How to Think About Science(20) :Basic Research and practical research on science (Wang R.J. Trans.). Journal of Huaiyin Teachers College(Social Sciences Edition), 38(4): 453-461.

[8] Zhu, J.X. (2018). The Legitimacy Dilemma, Causes and Mechanism Construction of Transformation of Local Colleges and Universities to Application-oriented Universities. Research in Higher Education of Engineering, 36(5): 117-122.

[9] Dubina, I.N., Carayannis, E.G., Campbell, D.F.J. (2012). Creativity Economy and a Crisis of the Economy? Coevolution of Knowledge, Innovation, and Creativity, and of the Knowledge Economy and Knowledge Society. Journal of the Knowledge Economy, 3(1): 1-24. 